\title{
Alterações bioquímicas em cães citopênicos e não citopênicos com ehrlichiose
}

\section{Biochemical changes in pancytopenic and non pancytopenic dogs with ehrlichiosis}

\author{
Vamilton Alvares Santarém ${ }^{1 *}$; Melina de Deus José2; Cecília Braga Laposy ${ }^{3}$
}

\section{Resumo}

Com o objetivo de estudar os parâmetros bioquímicos associados às funções renal e hepática em cães naturalmente infectados por Ehrlichia canis e associá-los à ehrlichiose, foram colhidas 57 amostras de sangue, com realização de dosagem de proteína plasmática total, albumina, globulina, relação albumina/ globulina (A/G), uréia, creatinina, alanino aminotransferase (ALT) e fosfatase alcalina (FA). Outros 35 cães em higidez foram utilizados como controle. Foram comparadas as médias dos animais infectados e controle, bem como a distribuição de freqüências, para associação dos resultados com a doença. Hipoproteinemia, hipoalbuminemia, redução da A/G, hiperglobulinemia e aumento de uréia estiveram associados à doença $(p<0,05)$. Foram comparados também os achados entre animais não pancitopênicos (NPan) e em pancitopenia (Pan), verificando-se que no primeiro grupo, houve aumento de ALT, e nos animais pancitopênicos, a creatinina foi o principal indicador de ehrlichiose. No caso do perfil protéico, não houve diferença que pudesse servir como marcador da fase da enfermidade nos animais infectados.

Palavras-chave: Canino, ehrlichiose, rickettsiose, bioquímica

\begin{abstract}
In order to study the biochemical changes in naturally infected dogs with Ehrlichia canis, blood samples from 57 animals were collected. Thirty-five healthy dogs were used as control group. Dosage of serum protein, albumin, globulin, albumin:globulin ratio $(\mathrm{A}: \mathrm{G})$, urea, creatinine, alanine aminotransferase (ALT) e alkaline phosphatase (AP) were carried out. The comparison of mean in infected and control group as well as the distribution of frequencies were investigated in order to associate the disease to the findings. Hypoproteinemia, hypoalbuminemia, decreased A:G ratio, hyperglobulinemia, and uremia were associated to ehrlichiosis $(\mathrm{p}<0.05)$. Regarding pancytopenia, it was observed that ALT and creatinine were, respectively, the marker of ehrlichiosis in non pancytopenic (NP) and pancytopenic (P) dogs. There were no significantly differences in protein profile in NP and P dogs that support the presence of a marker for the disease.
\end{abstract}

Key words: Canine, ehrlichiosis, rickettsiosis, biochemistry

1 Professor, Doutor, Laboratório de Medicina Veterinária Preventiva e Saúde Pública II (Parasitologia). Hospital Veterinário da Universidade do Oeste Paulista (Unoeste). Presidente Prudente, São Paulo. E-mail: vamilton@unoeste.br.

2 Médica Veterinária autônoma.

3 Professora, Doutora, Laboratório de Patologia Clínica Veterinária (Unoeste) - Presidente Prudente, São Paulo.

* Autor para correspondência 


\section{Introdução}

A ehrlichiose monocítica é uma doença infecciosa transmitida pelo carrapato Rhipicephalus sanguineus e ocasionada pela bactéria Ehrlichia canis (WOODY; HOSKINS, 1991), que pode acometer animais de todas as raças e idades e de ambos os sexos (SANTARÉM, 2003).

Em animais naturalmente infectados, é difícil determinar a fase da doença em que o animal se encontra, aguda, subclínica ou crônica (NEER, 1998), uma vez que a apresentação clínica e os achados laboratoriais são bastante similares (WADDLE, LITTMAN, 1988) e a duração e severidade dos sinais clínicos são variáveis (HUXSOLL et al., 1972).

O sucesso do tratamento depende de um diagnóstico precoce, que deve ser realizado na fase inicial da doença para melhora do prognóstico (ANDEREG; PASSOS, 1999). O diagnóstico pode ser realizado por métodos sorológicos, cultivo celular, reação em cadeia de polimerase (PCR), achados de mórulas e associação de achados clínicos e hematológicos.

Alguns dos métodos são caros, enquanto outros podem ter seu processamento demorado ou apresentar sensibilidade muito baixa ou resultados falso-negativos ou falso-positivos, o que muitas vezes dificulta o clínico a estabelecer que critérios devem ser adotados para confirmação da doença (KAKOMA et al., 2000).

Os estudos clínico-laboratoriais têm sido fundamentados basicamente nas alterações clínicas e nos achados hematológicos, e com a proposta de uma caracterização da doença nas diversas regiões em que ela ocorre e na diversidade da patogenicidade das diferentes cepas.

Os dados sobre alterações bioquímicas, porém, são bastante escassos na literatura. Dessa forma, o objetivo do presente estudo foi o de estudar a bioquímica renal e hepática em animais naturalmente infectados por E.canis, comparando as alterações em animais pancitopênicos e não pancitopênicos, possibilitando uma associação entre as alterações bioquímicas e a fase da ehrlichiose.

\section{Material e Métodos}

\section{Local do estudo}

Durante o período de 12 meses, amostras de soro de 57 cães procedentes do município de Presidente Prudente, foram colhidas para realização do perfil bioquímico renal (uréia e creatinina) e hepático (fosfatase alcalina e alanino aminotransferase).

As amostras foram obtidas por meio de estudo prospectivo valendo-se de atendimentos no Hospital Veterinário da Universidade do Oeste Paulista Unoeste (HV).

\section{Critérios de inclusão}

Foram selecionados os animais procedentes de Presidente Prudente, que não tinham sido encaminhados ao Hospital Veterinário por outros profissionais da cidade e que não haviam recebido medicamentos, como antibióticos ou antiinflamatórios os quais poderiam comprometer a análise dos resultados.

\section{Triagem clínica}

Foram considerados como suspeitos, os cães nos quais foram constatados dois sinais clínicos relacionados por Kakoma et al. (2000): apatia, anorexia, emaciação, letargia, sinais de depressão, febre, temperatura retal maior que $39,5^{\circ} \mathrm{C}$, palidez de mucosas, ou sinais de distúrbio de coagulação como epistaxe, petéquias, sufusões, melena, hematúria ou hifema.

\section{Triagem laboratorial}

Os animais com uma ou mais das alterações hematológicas descritas por Kakoma et al. (2000) e que consistiam de trombocitopenia, anemia, leucopenia, pancitopenia, hipoproteinemia, ou presença de mórulas, passaram para a última fase de triagem, que constou da verificação de mórulas em esfregaços de sangue. 


\section{Grupo controle}

Trinta e cinco animais em higidez foram selecionados no Canil da Unoeste, a fim de comparar os valores do perfil bioquímico.

\section{PCR}

A Reação em Cadeia de Polimerase foi realizada com a utilização de nested-PCR, para confirmação de infecção por E. canis, conforme protocolo empregado no Laboratório de Virologia do Instituto de Biociências da Unesp, Botucatu, São Paulo, segundo critérios descritos por Wen et al. (1997).

\section{Colheita das amostras}

Amostras de sangue foram colhidas por punção da jugular com auxílio de tubos de vácuo (Vacuntainer $^{\mathbb{R}}$ ), para os seguintes procedimentos:

- 4,0 mL em EDTA a 10\% para pesquisa de hematozoário, realização do hemograma e determinação dos valores da proteína total plasmática, fibrinogênio e número de plaquetas segundo Jain (1993).

- 5,0 mL de sangue total, para obtenção de soro e realização das análises bioquímicas(KANEKO; HARVEY; BRUSS, 1997).

\section{Processamento das amostras}

As dosagens bioquímicas foram realizadas de acordo com Kaneko, Harvey e Bruss (1997), utilizando-se as seguintes técnicas recomendadas pelo fabricante (Labtest):

- Proteína sérica total: método do Biureto.

- Albumina: método Verde de Bromocresol.

- Uréia: pela urease (Salicilato e Hipoclorito de Sódio).

- Creatinina: pelo Picrato em meio alcalino.

- Alanino aminotransferase: método de Reitman e Frankel.
- Fosfatase Alcalina: método de Roy, modificado.

- Fibrinogênio plasmático: método de precipitação pelo calor a $56{ }^{\circ} \mathrm{C}$.

- Proteína plasmática total: por refratometria.

- Hemograma: contagem de hemácias, leucócitos e dosagem de hemoglobina pelo contador automático de células (Celm CC 530), de acordo com Jain (1993).

- Contagem diferencial de leucócitos: esfregaço sanguíneo utilizando coloração de rápida pelo Diff-Quik.

- Contagem de plaquetas: método do hemocitômetro.

- Pesquisa de hematozoários: realização de lâminas com papa leucocitária, obtida pela centrifugação de microtubos capilares, coradas pelo Diff-Quik.

\section{Análise estatística}

O software GraphPad Instat foi usado para realização da análise estatística. Para comparação de média dos valores bioquímicos, entre animais infectados e controle, bem como dos animais em pancitopenia e não pancitopênicos, os dados foram submetidos ao teste $\mathrm{t}$ de Student. As possíveis associações entre as variáveis bioquímicas foram identificadas pelo teste exato de Fischer, com cálculo do odds-ratio e intervalo de confiança de $95 \%$. Os dados foram considerados significantes ao nível de $5 \%$.

\section{Resultados}

Na tabela 1 são apresentados os resultados dos valores de bioquímica mínimos e máximos, e da comparação das médias dos animais infectados e do grupo controle. A distribuição de freqüências entre os dois grupos e a associação das variáveis bioquímicas à ehrlichiose são apresentadas na Tabela 2. 
Tabela 1. Valores médios (mínimos-máximos) de achados de bioquímica em cães naturalmente infectados por Ehrlichia canis e grupo controle, Presidente Prudente, 2007, e valores de referências, segundo Kaneko, Harvey e Bruss (1997).

\begin{tabular}{|c|c|c|c|c|}
\hline & \multicolumn{3}{|c|}{ Achados } & \multirow{2}{*}{$\begin{array}{l}\text { Valores de } \\
\text { Referência }\end{array}$} \\
\hline & Doentes $(\mathrm{n}=57)$ & $\begin{array}{l}\text { Controle } \\
(\mathrm{n}=35)\end{array}$ & p-value & \\
\hline Proteína Plasmática Total (g/dL) & $\begin{array}{c}6,765 \\
(2,15-11,47)\end{array}$ & $\begin{array}{c}6,806 \\
(5,4-8,86)\end{array}$ & 0,8977 & $5,8-7,1$ \\
\hline $\begin{array}{l}\text { Albumina } \\
(\mathrm{g} / \mathrm{dL})\end{array}$ & $\begin{array}{c}1,602 \\
(0,67-2,51)\end{array}$ & $\begin{array}{c}2,343 \\
(2,1-2,87)\end{array}$ & $<0,0001 *$ & $2,6-3,3$ \\
\hline $\begin{array}{l}\text { Globulina } \\
\text { (g/dL) }\end{array}$ & $\begin{array}{c}5,163 \\
(1,48-10,9)\end{array}$ & $\begin{array}{c}4,458 \\
(3,16-7,24)\end{array}$ & $0,0351^{*}$ & $2,7-4,4$ \\
\hline Redução Relação A/G & $\begin{array}{c}0,3523 \\
(0,1-0,66)\end{array}$ & $\begin{array}{c}0,558 \\
(0,28-0,88)\end{array}$ & $<0,0001^{*}$ & $0,59-1,11$ \\
\hline $\begin{array}{l}\text { Uréia } \\
\text { (mg/dL) }\end{array}$ & $\begin{array}{c}56,321 \\
(19,5-126,42)\end{array}$ & $\begin{array}{c}39,425 \\
(20,5-58,61)\end{array}$ & $0,0021 *$ & $20,0-60,0$ \\
\hline $\begin{array}{l}\text { Creatinina } \\
(\mathrm{mg} / \mathrm{dL})\end{array}$ & $\begin{array}{c}1,077 \\
(0,42-3,0)\end{array}$ & $\begin{array}{c}0,9797 \\
(0,6-1,5)\end{array}$ & 0,22 & $0,5-1,5$ \\
\hline Alanino Aminotransferase (UI/L) & $\begin{array}{c}131,96 \\
(24,1-574,6)\end{array}$ & $\begin{array}{c}101,99 \\
(24,1-279,5)\end{array}$ & 0,0801 & $21,0-102,0$ \\
\hline $\begin{array}{c}\text { Fosfatase Alcalina } \\
\qquad(\mathrm{mg} / \mathrm{dL})\end{array}$ & $\begin{array}{c}38,235 \\
(5,2-236,6)\end{array}$ & $\begin{array}{c}17,872 \\
(10,1-49,2)\end{array}$ & $0,0003^{*}$ & $20,0-156,0$ \\
\hline
\end{tabular}

A/G: Albumina/Globulina * valor de significância $\mathrm{p}<0,05$

Tabela 2. Distribuição de freqüências (\%) e Odds Ratio de acordo com variáveis bioquímicas associadas com a infecção de animais por Ehrlichia canis, Presidente Prudente, São Paulo.

\begin{tabular}{|c|c|c|c|c|c|c|}
\hline \multirow[b]{2}{*}{ Variável } & & \multicolumn{2}{|c|}{ Freqüência (\%) } & \multirow[t]{2}{*}{ OR } & \multirow[t]{2}{*}{$\mathrm{IC}$} & \multirow[t]{2}{*}{$p$} \\
\hline & & Infectado & Controle & & & \\
\hline \multirow{2}{*}{ Hipoproteinemia } & Não & 41 & 34 & & & \\
\hline & Sim & 21 & 4 & 3,875 & $1,193-12,588$ & $0,025^{*}$ \\
\hline \multirow{2}{*}{ Hiperproteinemia } & Não & 36 & 27 & & & \\
\hline & Sim & 26 & 11 & 1,818 & $0,7373-4,484$ & 0,2662 \\
\hline \multirow{2}{*}{ Hipoalbuminemia } & Não & 1 & 16 & & & \\
\hline & Sim & 61 & 22 & 42,0 & $5,204-338,94$ & $<0,0001 *$ \\
\hline \multirow{2}{*}{ Hiperglobulinemia } & Não & 29 & 28 & & & \\
\hline & Sim & 33 & 10 & 3,21 & $1,28-8,05$ & $0,0164 *$ \\
\hline \multirow{2}{*}{ Redução relação A/G } & Não & 4 & 16 & & & \\
\hline & Sim & 58 & 22 & 9,938 & $2,942-33,568$ & $<0,0001 *$ \\
\hline \multirow{2}{*}{ Aumento Uréia } & Não & 48 & 37 & & & \\
\hline & Sim & 14 & 1 & 10,045 & $1,251-80,66$ & $0,0142 *$ \\
\hline \multirow{2}{*}{ Aumento Creatinina } & Não & 57 & 38 & & & \\
\hline & Sim & 5 & 0 & 7,438 & $0,398-138,87$ & 0,1524 \\
\hline \multirow{2}{*}{ Aumento ALT } & Não & 33 & 25 & & & \\
\hline & Sim & 29 & 13 & 1,725 & $0,7223-4,120$ & 0,2786 \\
\hline \multirow{2}{*}{ Aumento FA } & Não & 61 & 38 & & & \\
\hline & Sim & 1 & 0 & 1,885 & $0,074-47,595$ & 1,0 \\
\hline
\end{tabular}

OR: Odds Ratio; IC: Intervalo de confiança; * Valor de significância $\mathrm{p}<0,05$;

A/G: Albumina/Globulina; ALT: Alanino aminotransferase; FA: Fosfatase alcalina 
Quando comparados às médias entre animais infectados e controle, não houve diferença em relação à proteína plasmática total. Entretanto, quando houve fracionamento, a albumina e a relação $\mathrm{A} / \mathrm{G}$ foram menores nos animais infectados em relação ao grupo controle $(p<0,0001)$. Por outro lado, a globulina nos animais infectados foi significativamente maior $(\mathrm{p}<0,05)$.

Em relação à distribuição das freqüências, as variáveis hipoproteinemia $(\mathrm{p}<0,05)$, hipoalbuminemia $(<0,0001)$, hiperglobulinemia $(p<0,05)$ e diminuição da relação $\mathrm{A} / \mathrm{G}(\mathrm{p}<0,0001)$ estiveram associadas com a infecção por E.canis.

No caso da uréia, da creatinina e da FA, os valores médios estavam dentro dos considerados de normalidade para a espécie. Contudo, no grupo de animais infectados, as médias de uréia e de FA foram significativamente superiores àquelas obtidas no grupo controle. Em relação à ALT, a média do grupo de animais infectados estava acima dos valores de referência $(131,96 \mathrm{UI} / \mathrm{L})$ mas não houve diferença quando comparada ao grupo controle. Porém, quando foi realizada a associação da infecção dos animais por E. canis com essas variáveis (Tabela 2), apenas o aumento da uréia apresentou significância.

Quando comparados os valores do perfil bioquímico dos animais infectados, a ALT foi a única variável em que as médias de cães não pancitopênicos foi superior ao daqueles em pancitopenia $(\mathrm{p}<0,05)$, com valores médios acima dos adotados como referência (Tabela 3). Entretanto, quando da distribuição da freqüência de variáveis bioquímicas, o aumento de creatinina e de ALT teve associação, respectivamente, com pancitopenia e sem pancitpoenia (Tabela 4).

Tabela 3. Valores médios de achados de bioquímicas renal e hepática de cães naturalmente infectados por Ehrlichia canis, pancitopênicos (P) e não pancitopênicos (NP), Presidente Prudente, 2007, e valores de referências, segundo Kaneko, Harvey e Bruss (1997)

\begin{tabular}{ccccc}
\hline & \multicolumn{3}{c}{ Achados } & \\
\cline { 2 - 4 } & $\mathrm{P}$ & $\mathrm{NP}$ & Valores de Referência \\
\cline { 2 - 4 } & $(\mathrm{n}=18)$ & $(\mathrm{n}=39)$ & $\mathrm{p}$-value & \\
\hline Proteína Plasmática Total (g/dL) & 6,569 & 6,855 & 0,6577 & $5,8-7,1$ \\
Albumina (g/dL) & 1,522 & 1,638 & 0,3568 & $2,6-3,3$ \\
Globulina (g/dL) & 5,047 & 5,217 & 0,7866 & $2,7-4,4$ \\
Redução Relação A/G & 0,3572 & 0,35 & 0,8751 & $0,59-1,11$ \\
Uréia (mg/dL) & 59,461 & 54,871 & 0,7488 & $20,0-60,0$ \\
Creatinina (mg/dL) & 1,149 & 1,044 & 0,5331 & $0,5-1,5$ \\
Alanino Aminotransferase (UI/L) & 82,86 & 154,32 & $0,0016^{*}$ & $21,0-102,0$ \\
Fosfatase Alcalina (mg/dL) & 27,1439 & 43,356 & 0,0678 & $20,0-156,0$ \\
\hline
\end{tabular}

A/G: Albumina/Globulina * valor de significância $\mathrm{p}<0,05$ 
Tabela 4. Comparação de freqüência das variáveis bioquímicas e Odds Ratio, em cães infectados por Ehrlichia canis em pancitopenia (P) e não pancitopênicos (NP), Presidente Prudente, 2007.

\begin{tabular}{|c|c|c|c|c|c|}
\hline \multirow[b]{2}{*}{ Variável } & \multicolumn{2}{|c|}{ Freqüência } & \multirow[b]{2}{*}{ OR } & \multirow[b]{2}{*}{ IC } & \multirow[b]{2}{*}{$p$} \\
\hline & $\mathrm{P}$ & NP & & & \\
\hline Hipoproteinemia & 11 & 23 & 1,0 & $0,3057-3,271$ & 1,0 \\
\hline Hiperproteinemia & 14 & 28 & 1,15 & $0,3723-3,552$ & 0,8080 \\
\hline Hipoalbuminemia & 32 & 67 & 1,442 & $0,05595-37,144$ & 1,0 \\
\hline Hiperglobulinemia & 18 & 35 & 1,188 & $0,3866-3,647$ & 0,7839 \\
\hline Redução Relação A/G & 28 & 65 & 0,4324 & $0,05587-3,347$ & 0,5835 \\
\hline Aumento Uréia & 5 & 18 & 0,58 & $0,1383-2,432$ & 0,5198 \\
\hline Aumento Creatinina & 7 & 2 & 10.857 & $1,115-105,72$ & $0,0305^{*}$ \\
\hline Aumento ALT & 7 & 42 & 0,1786 & $0,04939-1,6456$ & $0,0096^{*}$ \\
\hline
\end{tabular}

OR: Odds Ratio; IC: Intervalo de confiança; *valor de significância p $<0,05$

A/G: Albumina/Globulina; ALT: Alanino aminotransferase

No caso da FA, não foi possível calcular a associação, uma vez que apenas um animal apresentou aumento da atividade enzimática.

\section{Discussão}

As alterações protéicas em cães com ehrlichiose têm sido atribuídas a diversos fatores. A hipoalbuminemia pode ser conseqüência de anorexia e diminuição da ingestão de proteína, perda de sangue para fluidos inflamatórios edematosos como conseqüência de vasculite, e ocorrer em qualquer fase da doença. Ela pode ser resultado ainda da redução de proteína devido à injúria hepática ou renal (WOODY; HOSKINS, 1991). Contudo, em cães experimentalmente infectados, na fase aguda ocorre uma redução de albumina pela perda renal e não pela disfunção hepática (CODNER; MASLIN, 1992).

A hiperglobulinemia, por sua vez, pode ser conseqüência do estímulo antigênico promovido pela bactéria, que desencadeia uma resposta humoral com a produção excessiva de globulinas (TIZARD, 2000). Essa produção pode levar a um quadro de hiperviscosidade sangüínea (CODNER; MASLIN, 1992), e, como mecanismo compensatório, o organismo elimina albumina pela urina, resultando em hipoalbuminemia, para manutenção da pressão oncótica (WOODY; HOSKINS, 1991). Provavelmente, essa foi a causa da associação da ehrlichiose com hipoproteinemia por hipoalbuminemia, hiperglobulinemia e redução da relação $\mathrm{A} / \mathrm{G}$, observada no presente estudo.

As alterações protéicas mostraram-se importantes indicadores da doença, independentemente da fase em que o cão se encontra, haja vista que não houve diferença na freqüência desses achados nos animais em pancitopenia ou não.

Em relação às alterações bioquímicas, o número de animais com ehrlichiose e aumento nos valores de uréia foi significativo, quando comparado ao grupo controle (Tablea 2). Troy, Vulgammott e Turnwald (1980), contrariamente, verificaram uma baixa freqüência $(16,67 \%)$ de cães com aumento de uréia e creatinina.

O aumento de uréia pode estar relacionado com alguns fatores que afetam o metabolismo de nitrogênio. Entre eles, aumento do catabolismo protéico relacionado à infecção e febre, absorção gastrintestinal de sangue, trauma e ingestão de quantidades excessivas de proteínas (FINCO, 1997; KERR, 2003). Dos animais infectados e com elevação de uréia, a maioria pertencia ao grupo de animais não pancitopênicos (Tabela4). Esses animais apresentavam febre e foram considerados em fase 
aguda da ehrlichiose. Segundo Tizard (2000), na resposta de fase aguda às infecções, ocorre aumento do catabolismo protéico e febre. Na ehrlichiose, as hemorragias do trato gastrintestinal podem estar associadas à trombocitopenia (WOODY; HOSKINS, 1991). Dos animais que apresentaram pancitopenia, apenas três apresentavam quadro de desidratação. Provavelmente, a hematoquezia (dois animais) e a melena (um animal) foram responsáveis pelo aumento da uréia nesses cães.

A pancitopenia é uma alteração que ocorre principalmente nos casos crônicos de ehrlichiose (BUHLES JÚNIOR; HUXSOLL; HILDEBRANDT, 1975; WOODY; HOSKINS, 1991; RIKIHISA et al., 1994). Quando comparados os animais infectados, os valores séricos de creatinina foram maiores nos cães em pancitopenia, enquanto que a ALT foi superior naqueles não pancitopênicos. Esses achados indicam que as injúrias hepática e renal podem ocorre tanto na fase aguda quanto na fase crônica da ehrlichiose. No quadro agudo, a uréia e ALT seriam marcadores da doença, uma vez que não houve diferença para a freqüência de aumento de uréia dos animais de ambos os grupos.

No presente trabalho, a creatinina serviu como marcador da cronicidade da ehrlichiose, uma vez que ela indica a cronificação de lesão renal, em conseqüência da injúria da membrana basal dos glomérulos devido ao aumento de anticorpos e deposição de imunocomplexos (BURGHEN et al., 1971).

ALT e FA são as duas enzimas mais comumente usadas como marcadores de doença hepática em cães (GASKILL et al., 2005), e podem ser encontradas em cães com ehrlichiose (BURGHEN et al., 1971; CODNER; MASLIN, 1992; PERILLE; MATUS, 1991; WOODY; HOSKINS, 1991). Entretanto, a FA não apresentou nenhuma importância como indicador da enfermidade no estudo, sendo similar ao reportado por Troy, Vulgammott e Turnwald (1980), onde nenhum cão apresentou aumento da atividade da enzima. Embora a atividade possa estar ligada a processos agudos ou crônicos de lesão hepática, a sua elevação é indicativa especialmente de colestase (KANEKO; HARVEY; BRUSS, 1997), que não estaria presente nos casos de ehrlichiose.

No caso da ALT, a sua atividade é fulgaz, e altas concentrações podem retornar à normalidade dentro de 24 horas (KANEKO; HARVEY; BRUSS, 1997). Em casos de cirrose hepática, hepatite progressiva crônica e neoplasia hepática, por exemplo, os valores tendem a estar dentro da normalidade (SEVELIUS, 1995; WILLARD; TVEDTEN, 1999). Entretanto, esses achados não descartam a possibilidade de hepatite crônica (FUENTEALBA et al., 1997; WILLARD; TVEDTEN, 1999). Esse provavelmente foi o perfil da enzima nos animais estudados, uma vez que apenas nos casos agudos de ehrlichiose houve aumento de sua atividade. Ou seja, não é possível descartar uma lesão hepática em cães na fase crônica da doença, embora o marcador, no caso a ALT, só possa ser detectado em casos agudos.

Dessa forma, conclui-se que a avaliação dos valores de uréia e creatinina, bem como das atividades de ALT e FA podem servir como indicadores de fases crônica e aguda da ehrlichiose.

\section{Agradecimentos}

Ao Prof. João Pessoa de Araújo, Laboratório de Virologia do Instituto de Biociências, Unesp, Botucatu, pelo processamento das amostras em Biologia Molecular.

\section{Referências}

ANDEREG, P. I.; PASSOS, L. M. F. Erliquiose canina - revisão. Clínica Veterinária, São Paulo, v. 4, n. 18, p. 31-38, 1999.

BUHLES JÚNIOR, W. C.; HUXSOLL, D. L.; HILDEBRANDT, P. K. Tropical canine pancytopenia: role of aplastic anemia in the phatogenesis of severe disease. Journal of comparative pathology, Edinburgh, v. 85 , n. 4, p. 511-521, 1975. 
BURGHEN, G. A .; BEISEL, W. R.; WALKER, J. S.; NIMS, R. N.; HUXSOLL, D. L.; HILDEBRANDT, P. K. Development of hypergammaglobulinemia in Tropical Canine Pancytopenia. American Journal of Veterinary Research, Chicago, v. 32, n. 5, p. 749-759, 1971.

CODNER, E. C.; MASLIN, W. R. Investigation of renal protein loss in dogs with acute experimentally induced Ehrlichia canis infection. American Journal of Veterinary Research, Chicago, v. 53, n. 3, p. 294-299, 1992.

FINCO, D. R. Kidney function. In: KANEKO, J. J.; HARVEY, J. W.; BRUSS, M. L. Clinical beochemistry of domestic animals. 5.ed. San Diego: Academic Press, 1997. p. 441-484.

FUENTEALBA, C.; GUEST, S.; HAYWOOD, S.; HORNEY, B. Chronic hepatitis: a retrospective study in 34 dogs. Canadian Veterinary Journal, Ottawa, v. 38, n. 6, p. 365-73, 1997.

GASKILL, C. L.; MILLER, L. M.; MATTOON, J. S.; HOFFMANN, W. E.; BURTON, S. A.; GELENS, H. C. J.; IHLE, S. L.; MILLER, J. B.; SHAW, D. H.; CRIBB, A. E. Liver histopathology and liver and serum alanine aminotransferase and alkaline phosphatase activities in epileptic dogs receiving Phenobarbital. Veterinary Pathology, Washington, v. 42, n. 2, p. 147-160, 2005.

HUXSOLL, D. L.; AMYX, H. L.; HEMELT, I. E.; HILDEBRANDT, P. K.; NIMS, R. M.; GOGHENOUR JÚNIOR, W. S. Laboratory studies of tropical canine pancytopenia. Experimental Parasitology, San Diego, v. 31, n. 1, p. 53-59, 1972.

JAIN, N. C. Essentials of veterinary hematology. Philadelpia: Lea \& Fabiger, 1993.

KAKOMA, I.; SAINZ, A.; TESOURO, M.; AMUSATEGUI, I.; KIM, C.; BIGGERTAFF, J.; McPEAK, J.; LEVY, M. G. Standardization of the diagnostic criteria for canine ehrlichiosis: towards a universal case definition. Annals of the New York Academy of Sciences, New York, v. 916, p. 396-403, 2000.

KANEKO, J. J.; HARVEY, J. W.; BRUSS, M. L. Clinical beochemistry of domestic animals. 5.ed. San Diego: Academic Press, 1997.

KERR, M. G. Substâncias nitrogenadas. In: Exames laboratoriais em medicina veterinária: bioquímica clínica e hematologia. 2.ed. São Paulo: Roca, 2003. p. 119-130.
NEER, T. M. Ehrlichiosis: Canine monocytic and granulocytic ehrlichiosis. In: GREENE, C. E. (Org). Infectious diseases of the dog and cat. 2.ed. Philadelphia: W. B. Saunders, 1998. p. 139-154.

PERILLE, A. L.; MATUS, R. E. Canine ehrlichiosis in six dogs with persistently increased antibody titters. Journal of Veterinary Internal Medicine, Philadelphia, v. 5, n. 3, p. 185-198, 1991.

RIKIHISA, Y.; YAMAMOTO, S.; KWAK, I.; IQBAL, Z.; KOCIBA, G.; MOTT, J.; CHICHANASIRIWITHAYA, W. C-reative protein and $\alpha 1$-acid glicoprotein levels in dogs infected with Ehrlichia canis. Journal of Clinical Microbiology, Washington, v. 32, n. 4, p. 912-917, 1994.

SANTARÉM, V. A. Achados epidemiológicos, clínicos e hematológicos, e comparação de técnicas para diagnóstico de Ehrlichia canis. 2003. Tese. (Doutorado em Medicina Veterinária) - Universidade Estadual Paulista Júlio de Mesquita Filho, Botucatu.

SEVELIUS, E. Diagnosis and prognosis of chronic hepatitis and cirrhosis in dogs. Journal of Small Animal Practice, Oxford, v. 36, n. 12, p. 521-528, 1995.

TIZARD, I. R. Innat imminity: inflamation. In:

(Ed.). Veterinary immunology: an introduction. 6.ed. Philadelphia: W.B. Saunders, 2000. p. 36-46.

TROY, G. C.; VULGAMMOTT, J. C.; TURNWALD, G. H. Canine ehrlichiosis: a retrospective study of 30 naturally occurring cases. Journal of the American Animal Hospital Association, Lakewood, v. 16, p. 181187, 1980.

WADDLE, J. R.; LITTMAN, M. P. A retrospective study of 27 cases of naturally occurring canine ehrlichiosis. Journal of the American Animal Hospital Association, Lakewood, v. 24, p. 615-620, 1988.

WEN, B.; RIKIHISA, Y.; MOTT, J. M.; GREENE, R.; KIM, H. Y.; ZHI, N.; COUTO, G. C.; UNVER, A.; BARTSH, R. Comparison of nested PCR with immunofluorescence-antibody assay for detection of Ehrlichia canis infection in dogs treated with doxycycline. Journal of Clinical Microbiology, Washington, v. 35, n. 7, p. 1852-1855, jul. 1997.

WILLARD, M. D.; TVEDTEN, H. Small animal clinical diagnosis by laboratory methods. 3.ed. Philadelphia: $\mathrm{W}$. B. Saunders, 1999. p. 172-207.

WOODY, B. J.; HOSKINS, J. D. Ehrlichial diseases of dogs. The Veterinary Clinics of North America: Small Animal Practice, Philadelphia, v. 21, n. 1, p. 75-98, 1991. 